\title{
Resting high frequency heart rate variability is not associated with the recognition of emotional facial expressions in healthy human adults.
}

\author{
Brice Beffara ${ }^{1,2,3}$, Nicolas Vermeulen $^{3,4}$, Martial Mermillod $^{1,2}$ \\ ${ }^{1}$ Univ. Grenoble Alpes, LPNC, F-38040, Grenoble, France \\ ${ }^{2}$ CNRS, LPNC UMR 5105, F-38040, Grenoble, France \\ ${ }^{3}$ IPSY, Université Catholique de Louvain, Louvain-la-Neuve, Belgium \\ ${ }^{4}$ Fund for Scientific Research (FRS-FNRS), Brussels, Belgium
}

\begin{abstract}
Author note
Correspondence concerning this article should be addressed to Brice Beffara, Office E250, Institut de Recherches en Sciences Psychologiques, IPSY - Place du Cardinal Mercier, 10 bte L3.05.01 B-1348 Louvain-la-Neuve, Belgium. E-mail: brice.beffara@univ-grenoble-alpes.fr

This study explores whether the myelinated vagal connection between the heart and the brain is involved in emotion recognition. The Polyvagal theory postulates that the activity of the myelinated vagus nerve underlies socio-emotional skills. It has been proposed that the perception of emotions could be one of this skills dependent on heart-brain interactions. However, this assumption was differently supported by diverging results suggesting that it could be related to confounded factors. In the current study, we recorded the resting state vagal activity (reflected by High Frequency Heart Rate Variability, HF-HRV) of 77 (68 suitable for analysis) healthy human adults and measured their ability to identify dynamic emotional facial expressions. Results show that HF-HRV is not related to the recognition of emotional facial expressions in healthy human adults. We discuss this result in the frameworks of the polyvagal theory and the neurovisceral integration model.
\end{abstract}

Keywords: HF-HRV; autonomic flexibility; emotion identification; dynamic EFEs; Polyvagal theory; Neurovisceral integration model

Word count: 9810

\section{Introduction}

The behavior of an animal is said social when involved in in- 20 teractions with other animals (Ward \& Webster, 2016). These ${ }^{21}$ interactions imply an exchange of information, signals, be- 22 tween at least two animals. In humans, the face is an efficient ${ }^{23}$ communication channel, rapidly providing a high quantity of 24 information. Facial expressions thus play an important role 25 in the transmission of emotional information during social 26 interactions. The result of the communication is the combina- ${ }^{27}$ tion of transmission from the sender and decoding from the ${ }^{28}$ receiver (Jack \& Schyns, 2015). As a consequence, the quality ${ }^{29}$ of the interaction depends on the ability to both produce and 30 identify facial expressions. Emotions are therefore a core ${ }^{31}$ feature of social bonding (Spoor \& Kelly, 2004). Health ${ }^{32}$ of individuals and groups depend on the quality of social ${ }_{33}$ bonds in many animals (Boyer, Firat, \& Leeuwen, 2015; S. L. 34 Brown \& Brown, 2015; Neuberg, Kenrick, \& Schaller, 2011), 35 especially in highly social species such as humans (Singer \& Klimecki, 2014).

The recognition of emotional signals produced by others is not independent from its production by oneself (Niedenthal, 2007). The muscles of the face involved in the production of a facial expressions are also activated during the perception of the same facial expressions (Dimberg, Thunberg, \& Elmehed, 2000). In other terms, the facial mimicry of the perceived emotional facial expression (EFE) triggers its sensorimotor simulation in the brain, which improves the recognition abilities (Wood, Rychlowska, Korb, \& Niedenthal, 2016). Beyond that, the emotion can be seen as the body -including braindynamic itself (Gallese \& Caruana, 2016) which helps to understand why behavioral simulation is necessary to understand the emotion.

The interplay between emotion production, emotion perception, social communication and body dynamics has been summarized in the framework of the polyvagal theory (Porges, 
2007). In a phylogenetic perspective, the polyvagal theory 89 describes how the interaction between the central and the 90 autonomic nervous systems underlie social behaviors. Heart 91 brain interactions are the core feature of the theory because 92 they shape the adaptation of an organism to environmental 93 variations. Indeed, social interactions precisely generate a 94 large amount of variability in the environment (Taborsky \& 95 Oliveira, 2012). Three major phylogenetic stages are iden-96 tified in the polyvagal theory and are all associated with a 97 specific physiological functioning. The most primitive stage 98 is supposed common to almost all the vertebrates. The behav-99 ioral function associated is immobilization and is underpinned ${ }_{100}$ by the unmyelinated branch of the vagus nerve connecting ${ }_{101}$ the heart and the brain. This function is a defense mecha-102 nism allowing to cope with highly dangerous events. The ${ }_{103}$ fight/flight response to danger is assumed to have emerged ${ }_{104}$ during a second and more recent stage and is dependent on ${ }_{105}$ the sympathetic-adrenal system. Finally, the third and last ${ }_{106}$ stage is proposed to characterize most of the mammals. The ${ }_{107}$ major physiological component of this stage is the myelinated ${ }_{108}$ branch of the vagus nerve which underlies self-soothing and prosocial/affiliative behaviors.

The myelinated vagus nerve quickly conducts information 111 between heart and brain resulting in modifications of heart 112 rate and heart contraction (Coote, 2013). The vagus nerve ${ }_{113}$ and the heart are connected at the level of the sinus node ${ }_{114}$ via acetylcholine. The sinus node contains high quantity of ${ }_{115}$ acetylcholinesterase, the acetylcholine is rapidly hydrolyzed, 116 and the delay of vagal inputs are short (Task Force of the ${ }_{117}$ European Society of Cardiology the North American Society ${ }_{118}$ of Pacing Electrophysiology (1996); Thayer2012a). Secondly,119 myelinated axonal conduction speed is high resulting in $\mathrm{a}_{120}$ quick reaction of the heart to the stimulation and to the stop of ${ }_{121}$ the stimulation (T. W. Ford \& McWilliam, 1986; Jones, Wang,122 \& Jordan, 1995; D. Jordan, 2005). High speed communication ${ }_{123}$ between the heart and the brain generates important variability ${ }_{124}$ in heart rate. This physiological variability allowed by vagal ${ }_{125}$ activity contributes to optimal regulation of the metabolism ${ }_{126}$ as a function of environmental changes and internal needs $\mathrm{s}_{127}$ (Porges, 1997; Thayer \& Sternberg, 2006).

Axons of the myelinated vagus nerve originates from pregan- ${ }^{129}$ glionic cardiac vagal neurons situated in the nucleus ambiguus ${ }^{130}$ (Porges, 1997). The nucleus ambiguus is a group of motor ${ }^{131}$ neurons from which the myelinated branch but also several ${ }^{132}$ sensory and motor fibers including the facial and trigeminal ${ }_{133}$ nerves emerge (Porges, 1998). The nucleus ambiguus has ${ }_{134}$ bidirectional connections with cortical (prefrontal, cingulate ${ }_{135}$ and insular) and sub-cortical (amygdala, hypothalamus) areas 136 (Thayer \& Lane, 2009). Theses regions play an important role ${ }_{137}$ in social cognition (Amodio \& Frith, 2006) and emotional pro-38 cessing (Lane et al., 2009). This implies that social communi- $\uparrow_{39}$ cation, cardiac vagal control and facial muscular control share ${ }_{140}$ common structural pathways. Constantly receiving updated ${ }_{141}$ information from external and internal changes, the nucleus ambiguus is the place of rapid central-periphery integration and reactivity toward emotional challenges (Coote, 2013; Porges, 1995). Afferent inputs to the facial motor nucleus are found (inter alia) in the nucleus ambiguus. The distribution of motoneurons supplying fast muscle contraction might underlie the complexity and mobility of facial expressions (Sherwood, 2005). The panel of available facial expressions could be the result of dynamic connections between cortical control, brainstem nuclei sensorimotor integration/inhibition and facial muscles activity (Porges, 2001) and may foster the ability to engage and regulate diversified social interactions (Sherwood, 2005). It is to notice that this proposition made by the polyvagal theory (Porges, 2001) seems plausible but has not been developed or tested specifically at an anatomofunctional level. Indeed, an important gap remains between the functions of neural connections and social skills. Evidence toward this hypothesis is mitigated so far (Sherwood, 2005) and needs to be tested further both at anatomical, physiological and behavioral levels.

Taken together, anatomo-functional characteristics of heartbrain-face interactions allow to predict that myelinated vagus nerve activity should be associated with the ability to process emotional facial signals involved in social communication (Porges, 2003). However, even if the literature cited above strongly corroborate the hypothesis formulated by Porges (1995), measures of vagal activity and emotion signal perception have not been recorded together until Bal et al. (2010) in healthy children and autistic children and Quintana, Guastella, Outhred, Hickie, \& Kemp (2012) in healthy human adults. They monitored the myelinated vagal heart-brain communication via the spectral analysis of heart rate variability which is a popular and reliable non-invasive tool reflecting the autonomic nervous system activity (Heathers, 2014; Task Force of the European Society of Cardiology the North American Society of Pacing Electrophysiology, 1996). Specifically, they extracted high frequency range of heart rate variability (HF-HRV) which provides a rigorous assessment of the myelinated heart-brain connection activity [Akselrod et al. (1981); Gary G Berntson et al. (1997); G. G. Berntson, Cacioppo, \& Quigley (1993); Gary G. Berntson, Norman, Hawkley, \& Cacioppo (2008); Cacioppo et al. (1994); M V Kamath \& Fallen (1993); M. V. Kamath, Upton, Talalla, \& Fallen (1992); M V Kamath, Upton, Talalla, \& Fallen (1992)).

Bal et al. (2010) evaluated facial emotion recognition with videos of dynamic EFEs (Dynamic Affect Recognition Evaluation, DARE) on the six basic emotions (sadness, fear, surprise, disgust, anger, and happiness, Porges, Cohn, Bal, \& Lamb (2007)). Videos displayed emotions going from neutral expression to apex through morphing. Quintana et al. (2012) evaluated facial emotion recognition by the Reading Mind in the Eyes Test (RMET, (Baron-Cohen, Jolliffe, Mortimore, \& Robertson, 1997; Baron-Cohen, Wheelwright, Hill, 
HF-HRV NOT ASSOCIATED WITH EMOTION RECOGNITION

Raste, \& Plumb, 2001)). The RMET is composed of pho-195 tographs displaying the eye-region of the facial expression of ${ }_{196}$ actors/actresses. The facial expressions corresponds to a feel-197 ing, a thinking or mental state. The photograph is displayed ${ }_{198}$ along with 4 labels describing possible mental states, among ${ }_{199}$ which only one actually corresponds to the picture. The task $k_{200}$ of the participants is therefore to "read in the mind" in order ${ }_{201}$ to identify the correct mental state. The work of Quintana et 202 al. (2012) is important because no data could bring evidence ${ }_{203}$ in favor of an association between vagal activity and the per-204 ception of social cues in healthy humans within the polyvagal ${ }_{205}$ framework (Porges, 1997) until them. The main result of $f_{206}$ their study is that HF-HRV is associated with better scores ${ }_{207}$ at the RMET, with items recoded such as correct answers 208 weight much for difficult trials versus easy ones. The authors ${ }_{209}$ conclude that higher levels of resting state HF-HRV are asso-210 ciated with better emotion recognition skills. Conversely, $\mathrm{Bal}_{211}$ et al. (2010) did not find any association between HF-HRV ${ }_{212}$ and emotion identification in healthy participants but only in ${ }_{213}$ children with autism spectrum disorders. Besides this results ${ }_{214}$ is observed only for response latency but not for accuracy) ${ }_{215}$ Fear, happiness and sadness were faster identified by higher ${ }_{216}$ resting-state HF-HRV participants.

On one side, Quintana et al. (2012) found that healthy adults ${ }^{218}$ were better at identifying mental states (when weighting for ${ }^{219}$ difficulty) and therefore proposed that HF-HRV is linked with ${ }^{220}$ emotion recognition. One the other side, Bal et al. (2010) did not find any association between HF-HRV and emotion identification (in healthy children). From here, 2 explana ${ }^{222}$ tions can emerge: i) The conceptual overlap between emotion recognition and mind reading found in Quintana et al. (2012) ${ }_{224}^{223}$ matters, and HF-HRV is associated with mental state reading ${ }_{225}$ bu not with emotion identification per se, iii) Considering healthy human participants, HF-HRV is associated with emotion recognition only in adults.

A study mixing the designs of Bal et al. (2010) and Quintanaz29 et al. (2012) can help to disentangle between these hypotheses 230 We report the results obtained after a protocol where resting ${ }_{231}$ state HF-HRV is measured in healthy adults. The emotion 232 identification task is similar to the Dynamic Affect Recogni-23з tion Evaluation software (DARE, Porges et al. (2007)) used $_{234}$ in Bal et al. (2010) (including anger, disgust, fear, joy, sad-235 ness and surprise) but included three more EFEs (contempt 236 embarrassment, and pride). All EFEs movies were from the 237 Amsterdam Dynamic Facial Expression Set (ADFES, Schalk 238 Hawk, Fischer, \& Doosje (2011)), a more recent database 239 with color stimuli. As a consequence, emotion identification 240 is based on a recent database with dynamic EFEs used in $\mathrm{Bal}_{241}$ et al. (2010) (anger, disgust, fear, joy, sadness and surprise) 242 $_{22}$ and 3 more (contempt, embarrassment, and pride) in order 243 to increase complexity. Even if this perspective is strongly $y_{24}$ challenged (Jack, Sun, Delis, Garrod, \& Schyns, 2016), some 245 authors suggest that the emotions used by Bal et al. (2010) 246 $_{26}$ are more basic and easier to identify compared to emotions more complex emotions such as contempt, embarrassment, and pride (Baron-Cohen, Golan, \& Ashwin, 2009). Contempt, embarrassment and pride are considered as "self-conscious" emotions but present typical morphological configurations at the level of the whole face (Schalk et al., 2011). Indeed, they involve facial muscular patterns or even slight movement of the head (Tracy \& Robins, 2008; Tracy, Robins, \& Schriber, 2009) and these patterns are to be decoded in order to identify the emotion. Albeit more complex than basic emotions, they differ from pure mental states because not concentrated on the eyes area.

As the distinction between basic and complex emotions fits the difference between our set of EFEs and the set used by Bal et al. (2010), it is relevant to rely on it as a factor of difficulty in EFEs recognition. Our design allows to assess if HF-HRV is associated with emotion recognition on a new set of dynamic whole EFEs. If HF-HRV is associated with emotion recognition in these conditions, this suggests that the task used by Bal et al. (2010) was not complex enough to establish the correlation and that HF-HRV is not discriminant for the recognition of "basic" emotions. On the contrary, if HF-HRV is not associated with emotion recognition, this would suggest that the results of Quintana et al. (2012) does not apply to emotion perception per se but rather to different "non-emotional" mechanisms involved in social signals reading (R. L. C. Mitchell \& Phillips, 2015).

\section{Methods}

In the "Methods" and "Data analysis" sections, we report how we determined our sample size, all data exclusions, all manipulations, and all measures in the study (Simmons, Nelson, \& Simonsohn, 2012).

Sample. Initial sample was composed of 77 young healthy human adults. Participants were recruited via advertisements (mailing list and poster). All participants were psychology students of University Grenoble-Alpes. Participants were French or perfectly bilingual in French. They provided written informed consent before the participation. The study was part of a global project reviewed and approved by the University human ethics committee from Grenoble, France (Grenoble ethics committee notice number 2014-05-13-49 and 2014-05-13-48). To be eligible, participants had to be aged between 18 and 60 years, with a normal or normal-tocorrected vision, explicitly reported an absence of psychiatric, neurologic, hormonal, or cardio-vascular disease, and with no medical treatment (with the exception of contraception). Smoking, energizing drinks (e.g. coffee, tea, etc...) and psychotropic substances (e.g. alcohol, cannabis, etc...) were prohibited to each participant the day of the experiment. They had also to avoid eating or drinking (water was allowed) the 2 hours preceding the experiment in order to limit the influence of digestion on autonomic functioning (Short term 
HRV measurement can be biased by the digestion of food since viscera are innervated by the autonomic nervous system (Heathers, 2014; Iorfino, Alvares, Guastella, \& Quintana, 2016; Quintana \& Heathers, 2014)) but they had to eat in the morning (more than 2 hours before the experiment) in order to avoid fasting states. The participants received experimental credits in return of their participation.

Sample size. We planned between 75 and 80 participants to take part in the study. Anticipating possible exclusions due to technical problems, we determined our sample size expecting at least 65 participants suitable for final analysis. This sample size was set on the basis of Quintana et al. (2012). Their sample size of 65 was adequate to observe an association between HF-HRV and the RMET score, with an effect size of $R^{2} \sim .07$.

Procedure. The experiment took place in a quiet and dimmed room. All participants were tested between 0900 $\mathrm{h}$ and $1300 \mathrm{~h}$. After a global description of the experiment, participants were asked to empty their bladder before starting the experiment. After that, they were taught how to install the

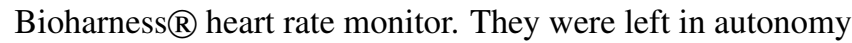
in an isolated room for the installation of the heart rate monitor. Then, they seated in a chair, the experimenter checked the signal and the experiment started. The instructions were to relax, breathe naturally and spontaneously. During 5 minutes, the participant watched short neutral samples of films selected and evaluated by Hewig et al. (2005) ("Hannah and her Sisters" and "All the President's Men") and Schaefer, Nils, Sanchez, \& Philippot (2010) ("Blue [1]", "Blue [2]", "Blue [3]" and "The lover"). Videos were displayed without audio. These 5 first minutes aimed to allow the participant to shift in a calm state. ECG data for HRV baseline computation was recorded during the 5 following minutes while participants listened to the first 5 minutes of a neutral audio documentary designed for laboratory studies (Bertels, Deliens, Peigneux, \& Destrebecqz, 2014). Neutral videos and audio documentary were used in order to standardize ECG recordings (Piferi, Kline, Younger, \& Lawler, 2000). ECG data was recorded during spontaneous breathing (Denver, Reed, \& Porges, 2007; Kobayashi, 2009; Kowalewski \& Urban, 2004; Larsen, Tzeng ${ }_{300}$ Sin, \& Galletly, 2010; Muhtadie, Koslov, Akinola, \& Mendes 2015; Pinna et al., 2007). After this first phase, the emotion identification task session started for about 15 minutes $\left(\mathrm{see}_{303}\right.$ description below). When this step ended, the participant ${ }_{304}$ completed computerized control surveys. The experimenter ${ }_{305}$ stayed out the room during the experiment but was available ${ }_{306}$ for eventual questions between the different steps of the experiment.

Emotion identification task. The emotion identification ${ }_{309}$ task followed the design used by Bal et al. (2010) and pro-s10 posed by Porges et al. (2007). Participants were presented ${ }_{311}$ with short video clips displaying dynamic standardized EFEs s12 $_{31}$ produced by humans adults. All the stimuli came from the $e_{313}$

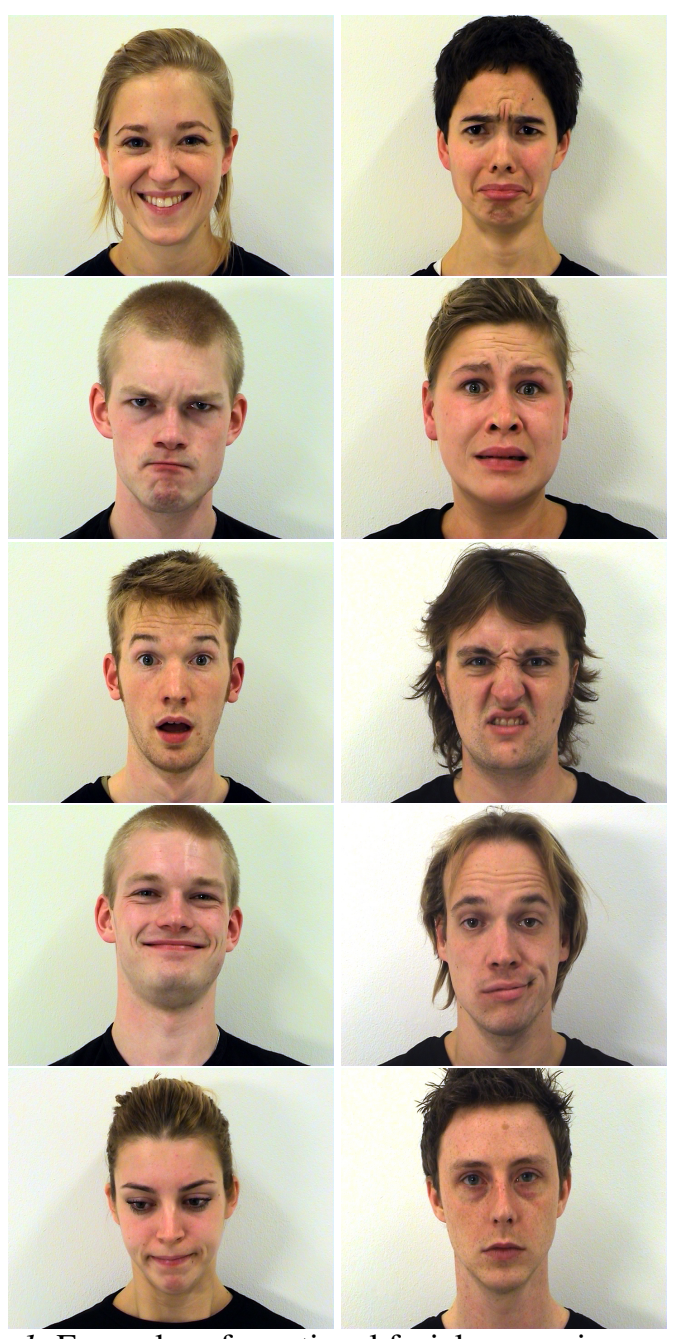

Figure 1. Examples of emotional facial expressions and of a neutral facial expression. From left to right and top to bottom: Joy (F03), Sadness (F04), Anger (M03), Fear (F05), Surprise (M02), Disgust (M04), Pride (M03), Contempt (M11), Embarras (F01), and Neutral (M12). All stimuli are from the ADFES (van der Schalk, Hawk, Fischer, \& Doosje, 2011).

ADFES (Schalk et al., 2011). Nine EFEs (Figure 1) of ten North-European models (5 males and 5 females: "F01", "F02", "F03", "F04”, "F05", "M02", "M03”, "M04”, “M11", and "M12") were presented in a random design. Video clips displayed the face of the model going from a neutral expression to the apex of the EFE. Video clips duration ranged from 6 to 6.5 seconds, including a neutral face for 0.5 seconds, followed by the onset of the EFE, and then the face held at apex for 5 seconds (Figure 2). In phase 1 of each trial, participants used the numeric pad of the computer keyboard to identify EFEs. The were asked to push the " 0 " key as soon as they could identify what emotion was expressed in the video video clip. Synchronous with the " 0 " key press, phase 2 started as the the video clip stopped and a new screen 


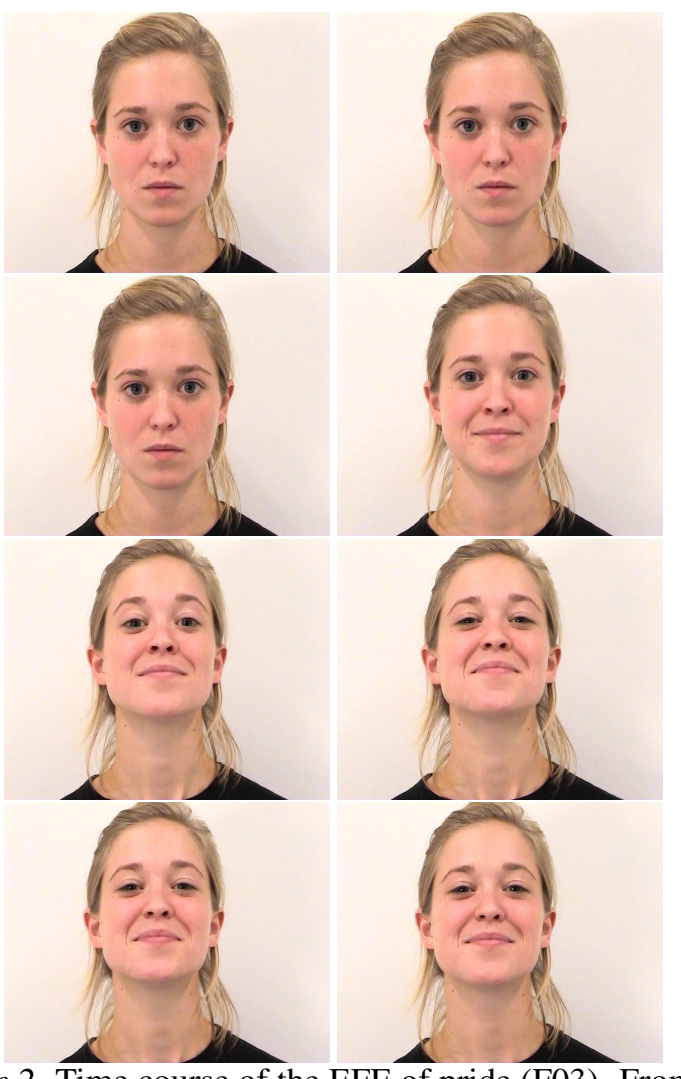

Figure 2. Time course of the EFE of pride (F03). From left ${ }_{361}$ to right and top to bottom, $\mathrm{t}=0,0.5,1,2,3,4,5,6$ seconds $_{362}$ Images are extracted from the original video set of the $\mathrm{ADFES}_{363}$ (van der Schalk, Hawk, Fischer, \& Doosje, 2011).

processing of facial emotional signals should allow to detect more subtle muscle movements of the face and therefore identify the emotion faster. Obviously, this method could also be influenced by different strategies of response but accuracy scores are available in order to assess the success of the recognition. As a consequence, performances in emotion recognition can be evaluated by both measures separately. The presence of 9 instead of 6 emotions (compared to Bal et al. (2010)) allows to increase the difficulty of the task and therefore induce variability in our data. Therefore, this design is closer to the design proposed by Quintana et al. (2012) with a large number of different emotions to categorize.

Physiological measurement. The electrocardiogram (ECG) data was recorded with a Zephyr Bioharness ${ }^{\mathrm{TM}} 3.0$ (Zephyr, 2014). The Bioharness ${ }^{\mathrm{TM}}$ is a class II medical device presenting a very good precision of measurement for ECG recording in low physical activity conditions (Johnstone, Ford, Hughes, Watson, \& Garrett, 2012a, 2012b; Johnstone et al., 2012). It has been used for ECG measurements in both healthy and clinical populations, presenting a very highto-perfect correlation with classical hospital or laboratory devices (Brooks et al., 2013; Yoon, Shah, Arnoudse, \& De La Garza, 2014). The Bioharness ${ }^{\mathrm{TM}}$ both provides comfort for the participant and allow reliable HRV extraction for the researcher (Lumma, Kok, \& Singer, 2015). The chest strap's sensor measures electrical activity corresponding to the classical V4 lead measurement (5th intercostal space at the midclavicular line) through conductive Lycra fabric. A single-ended ECG circuit detects QRS complexes and incorporates electrostatic discharge protection, both active and passive filtering and an analog-to-digital converter. Interbeat intervals are derived by Proprietary digital filtering and signal processed with a microcontroller circuit. The ECG sensor sampling frequency is $250 \mathrm{~Hz}$ and the resolution $0.13405 \mathrm{mV}$., ranging from 0 to $0.05 \mathrm{~V}$ (Villarejo, Zapirain, \& Zorrilla, 2013). After a slight moistening of the 2 ECG sensors, the chest-strap was positioned directly on the skin, at the level of the inframammary fold, under the lower border of the pectoralis major muscle. The recording module communicated with an Android $\AA$ OS smartphone by Bluetooth $\AA$. The application used to acquire the signal emitted by the Bioharness ${ }^{\mathrm{TM}}$ was developed, tested, and validated by Cânovas, Domingues, \& Sanches (2011). The Android $\AA$ OS device used to record the signal was an LG-P990 smartphone (Android® version 4.1.2.).

Control for confounding factors. To control for confounding variables likely to be linked to HRV, participants completed questionnaires detailing life habits, demographic data and emotional traits (Quintana et al., 2012). Physical activity was assessed with the International Physical Activity Questionnaire (IPAQ,Craig et al. (2003)), composed of 9 items that calculate an index reflecting the energy cost of physical activities (Metabolic Equivalent Task score, MET). The IPAQ has 
been validated in French (Briancon et al., 2010; Hagströmer, Oja, \& Sjöström, 2006) and widely used in French surveys (Salanave et al., 2012). Participants also completed the De- ${ }^{441}$ pression Anxiety and Stress scales (DASS-21;(P. F. Lovibond ${ }^{442}$ \& Lovibond, 1995)). The DASS-21 is a 21 -item question- ${ }^{443}$ naire, validated in French (Ramasawmy \& Gilles, 2012), and ${ }^{444}$ composed of three subscales evaluating depression, anxiety ${ }^{445}$ and stress traits. We also recorded the size, weight, age and ${ }^{44}$ sex of the participants and their daily cigarette consumption. ${ }^{447}$ Participants answered final surveys on a DELL latitude E6500 ${ }^{44}$ laptop. Surveys were built and displayed with E-prime soft- ${ }^{44}$ ware (E-prime 2.0.10.242 pro).

Physiological signal processing. R-R interval data was ex- ${ }^{45}$ tracted from the Android $囚$ device and imported into RHRV ${ }^{452}$ for Ubuntu (Rodríguez-Liñares et al., 2011). Signal was vi- ${ }^{453}$ sually inspected for artifact (Prinsloo et al., 2011; Quintana ${ }^{454}$ et al., 2012; Wells, Outhred, Heathers, Quintana, \& Kemp, 2012). Ectopic beats were discarded (Kemper, Hamilton, $\&^{456}$ Atkinson, 2007) for participants presenting a corrupted $\mathrm{RR}^{457}$ interval series (Beats per minute (bpms) shorter/longer than ${ }^{45}$ $25 / 180$ and/or bigger/smaller than $13 \%$ compared to the $50^{45}$ last bpms). RR series were interpolated by piecewise cubic ${ }^{460}$ spline to obtain equal sampling intervals and regular spectrum ${ }^{46}$ estimations. A sampling rate of $4 \mathrm{~Hz}$ was used. We then ${ }^{462}$ extracted the frequency component of HRV from RR interval ${ }^{463}$ data. The LF (0.04-0.15 Hz) and HF (0.15-0.4 Hz) compo- ${ }^{464}$ nents were extracted using an east asymmetric Daubechies ${ }^{46}$ wavelets with a length of 8 samples. Maximum error allowed ${ }^{466}$ was set as 0.01 (García, Otero, Vila, \& Márquez, 2013).

Model comparison. Model selection was completed using ${ }^{468}$ $A I C_{c}$ (corrected Akaike information criterion) and Evidence Ratios - $E R_{i}$ - (K. P. Burnham \& Anderson, 2004; Kenneth P. Burnham, Anderson, \& Huyvaert, 2011; Hegyi \& Garamszegi, ${ }^{47}$ 2011; Symonds \& Moussalli, 2011). $A I C_{c}$ provides a relative measure of goodness-of-fit but also of parsimony by sanction- ${ }^{473}$ ing models for their numbers of parameters. $A I C_{c}$ is more severe on this last point than $\mathrm{AIC}\left(A I C_{c}=A I C+\frac{2 K(K+1)}{n-K-1}\right.$ where $K$ is the number of parameters and $n$ the sample size.). We computed the difference between best (lower) and other $A I C_{c} s$ with $\Delta_{A I C_{c}}=A I C_{c_{i}}-A I C_{c_{\text {min }}}$. The weight of a model is then expressed as $w_{i}=\frac{e^{\frac{1}{2} \Delta_{A I C_{c_{i}}}}}{\sum_{r}^{R} e^{\frac{1}{2} \Delta_{A I C_{c_{r}}}}}$. From there, we can compute the Evidence Ratio: $E R_{i}=\frac{w_{\text {best }}}{w_{i}}$. Even if quantitative information about evidence is more precise, we also based our decision on Kass \& Raftery (1995) and Snipes \& Taylor (2014), i.e. minimal $\left(E R_{i}<3.2\right)$, substantial $\left(3.2<E R_{i}<10\right)$, strong $\left(10<E R_{i}<100\right)$ and decisive $\left(100<E R_{i}\right)$ evidence. If the model with the lower $A I C_{c}$ included more parameters than others, we considered it as relevant if the evidence was at least substantial. If the model with the lower $A I C_{c}$ included less parameters than others, we chose it even if evidence was minimal.

\section{Results}

Correlations between control variables and variables of interest are displayed in figures 3 and 4. Because weight was associated with HF-HRV, we adjusted HF-HRV for it by extracting the standardized residuals of the regression with weight as the independent variable and HF-HRV as the dependent variable (Quintana et al., 2012). HRV as an independent variable in the following analysis is therefore HF-HRV (normalized units) adjusted for weight.

In a second step, we selected the relevant random factors to include in our models. Whether for response times or accuracy, participants and items (i.e. the model (actor) performing the EFE) were appropriate as random factors. Indeed models including participants and items showed the lowest (best) AICc with $E R_{i}=0.936 / 0.064=14.62$ (strong evidence) for response times (Table 1) and $E R_{i}=0.967 / 0.033=29.30$ (strong evidence) for accuracy (Table 2).

We then compared the parsimony of models containing main effects (HF-HRV and emotion type) and interaction effects. Model comparison showed no evidence in favor of a main effect of HF-HRV or toward an interaction between HRV and emotion compared to the intercept model, either for response times or accuracy (tables 3 and 4. HF-HRV did not predict performance in emotion identification. This absence of effect was observed regardless of the emotion type ("complex" versus "basic"). There was minimal evidence $\left(E R_{i}=0.631 / 0.211=\right.$ 2.99 for response times and $E R_{i}=0.596 / 0.194=3.07$ for accuracy) toward and principal effect of emotion type compared to the second best model and decisive evidence compared to the intercept model (Figure 5) with a marginal $R^{2}$ of .06 and .05 respectively. Overall emotions absent from Bal et al. (2010) (i.e. "complex emotions") were more difficult to identify compared to the emotion they used (i.e. "basic" emotions). 


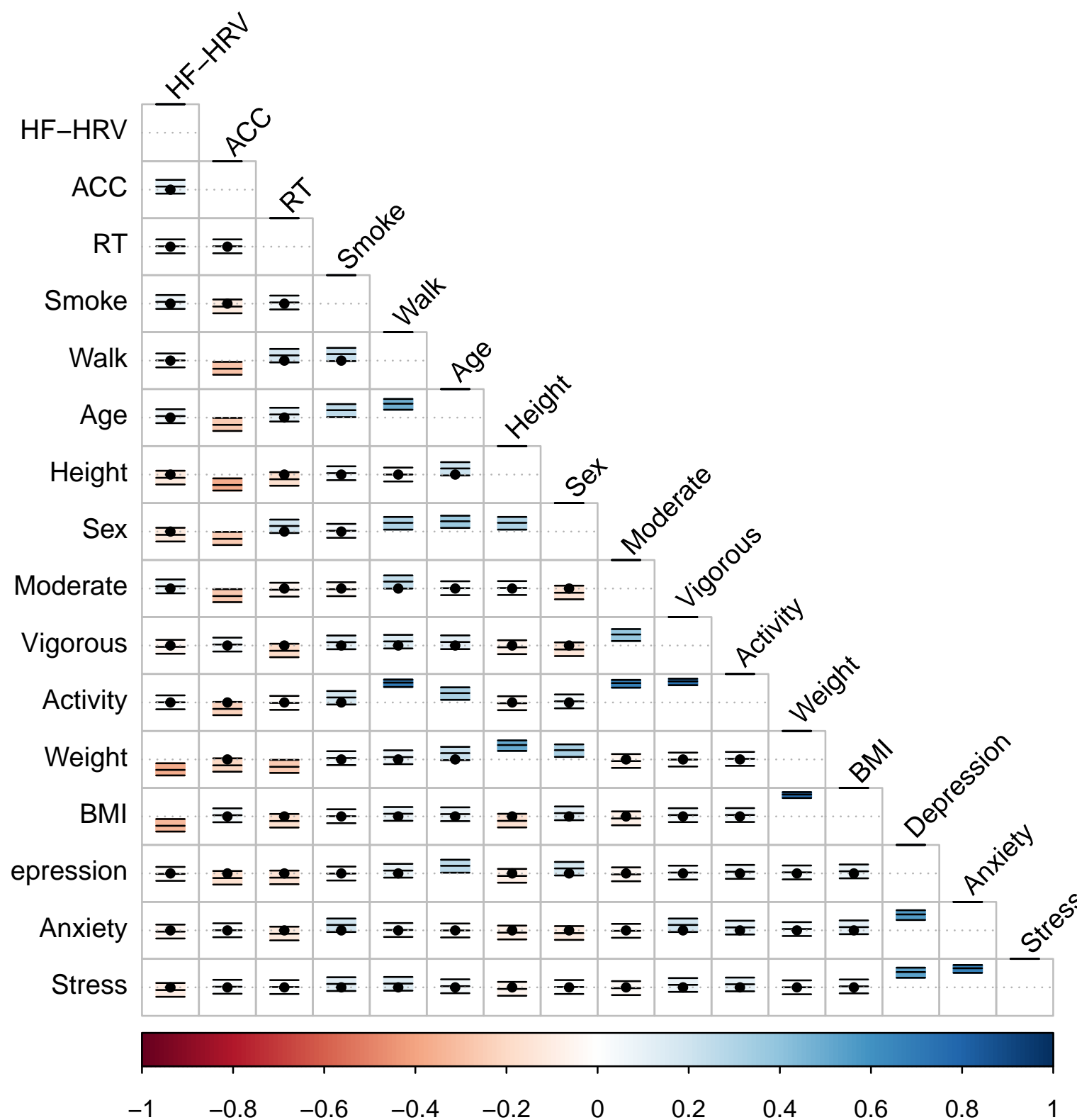

Figure 3. Correlation confidence intervals between recorded variables. Confidence regions represent $95 \%$ CIs and are marked with a black dot when including 0 .

Table 1

Comparison of random effects in models for response times, ordered by AICc relative to the model with the lowest (best) AICc.

\begin{tabular}{lcccc}
\hline & $K$ & $A I C c$ & $\Delta_{A I C c}$ & Weight \\
\hline ppt + item & 4 & 77486 & 0 & 0.936 \\
$p p t+$ item $+H R V_{\text {slope }}$ & 7 & 77491 & 5.366 & 0.064 \\
ppt & 3 & 77563 & 77.37 & 0 \\
item & 3 & 78383 & 896.9 & 0
\end{tabular}

Note. $K$ is the number of parameters in the model. ppt=participants, item = model of the video clip, $H R V_{\text {slope }}=$ random by-participant 
bioRxiv preprint doi: https://doi.org/10.1101/077784; this version posted September 27, 2016. The copyright holder for this preprint (which was not certified by peer review) is the author/funder, who has granted bioRxiv a license to display the preprint in perpetuity. It is made available under aCC-BY-NC-ND 4.0 International license.

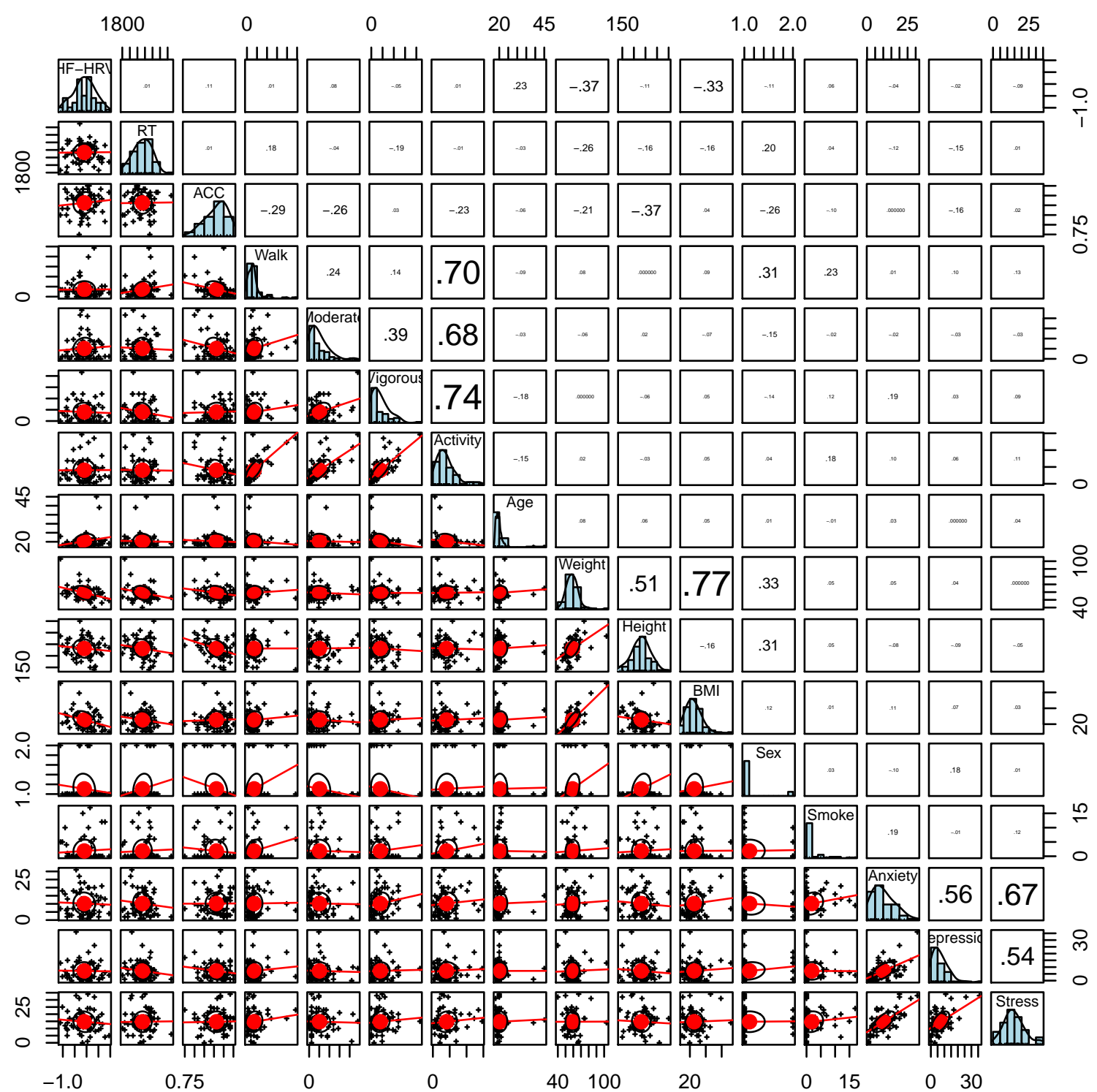

Figure 4. Scatter plots, distributions, and Pearson correlation coefficients between recorded variables. R values' font sizes are proportional to the strength of the correlation.

Table 2

Comparison of random effects in models for accuracy, ordered by AICc relative to the model with the lowest (best) AICc.

\begin{tabular}{lcccc}
\hline & $K$ & $A I C c$ & $\Delta_{A I C c}$ & Weight \\
\hline ppt + item & 3 & 4463 & 0 & 0.967 \\
ppt + item $+H R V_{\text {slope }}$ & 6 & 4469 & 6.739 & 0.033 \\
ppt & 2 & 4494 & 31.66 & 0 \\
item & 2 & 4516 & 53.21 & 0
\end{tabular}


bioRxiv preprint doi: https://doi org/10,1101/077784; this version posted September 27, 2016. The copyright holder for this preprint (which was not certified by peer review) is the author/funder, who has granted bioRxiv a license to display the preprint in perpetuity. It is made available under aCC-BY-NC-ND 4.0 International license.

HF-HRV NOT ASSOCIATED WITH EMOTION RECOGNITION

Table 3

Comparison of models for response times, ordered by AICc relative to the model with the lowest (best) AICc.

\begin{tabular}{lcccc}
\hline & $K$ & $A I C c$ & $\Delta_{A I C c}$ & Weight \\
\hline Int $+E m o$ & 5 & 77089 & 0 & 0.63 \\
Int $+H R V+E m o$ & 6 & 77091 & 2.188 & 0.21 \\
Int $+H R V+E m o+H R V * E m o$ & 7 & 77093 & 4.567 & 0.06 \\
Int $+H R V^{2}+E m o+H R V^{2} * E m o$ & 7 & 77093 & 4.567 & 0.06 \\
Int $+H R V+H R V^{2}+E m o+H R V * E m o+H R V^{2} * E m o$ & 9 & 77095 & 6.202 & 0.02 \\
Int & 4 & 77486 & 396.9 & 0 \\
Int $+H R V^{2}$ & 5 & 77486 & 397 & 0 \\
Int $+H R V$ & 5 & 77488 & 399 & 0 \\
Int $+H R V * E m o$ & 5 & 77488 & 399.1 & 0 \\
Int $+H R V+H R V^{2}$ & 6 & 77488 & 399.1 & 0
\end{tabular}

Table 4

Comparison of models for accuracy, ordered by AICc relative to the model with the lowest (best) AICC.

\begin{tabular}{lcccc}
\hline & $K$ & $A I C c$ & $\Delta_{A I C c}$ & Weight \\
\hline Int $+E m o$ & 4 & 4339 & 0 & 0.59 \\
Int $+H R V+E m o$ & 5 & 4341 & 2.243 & 0.19 \\
Int $+H R V+E m o+H R V * E m o$ & 6 & 4343 & 3.994 & 0.08 \\
Int $+H R V^{2}+E m o+H R V^{2} * E m o$ & 6 & 4343 & 3.994 & 0.08 \\
Int $+H R V+H R V^{2}+E m o+H R V * E m o+H R V^{2} * E m o$ & 8 & 4344 & 5.03 & 0.04 \\
Int & 3 & 4463 & 123.8 & 0 \\
Int $+H R V^{2}$ & 4 & 4464 & 125.1 & 0 \\
Int $+H R V * E m o$ & 4 & 4464 & 125.3 & 0 \\
Int $+H R V$ & 4 & 4465 & 126 & 0 \\
Int $+H R V+H R V^{2}$ & 5 & 4466 & 127.4 & 0
\end{tabular}

Note. $K$ is the number of parameters in the model. Int = Intercept, HRV = resting HF-HRV, Emo = Type of emotion (present in Bal et al. (2010) versus not). All models include participants and items as random factors. 
bioRxiv preprint doi: https://doi.org/10.1101/077784; this version posted September 27, 2016. The copyright holder for this preprint (which was not certified by peer review) is the author/funder, who has granted bioRxiv a license to display the preprint in perpetuity. It is made available under aCC-BY-NC-ND 4.0 International license.

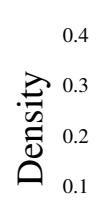

0.0
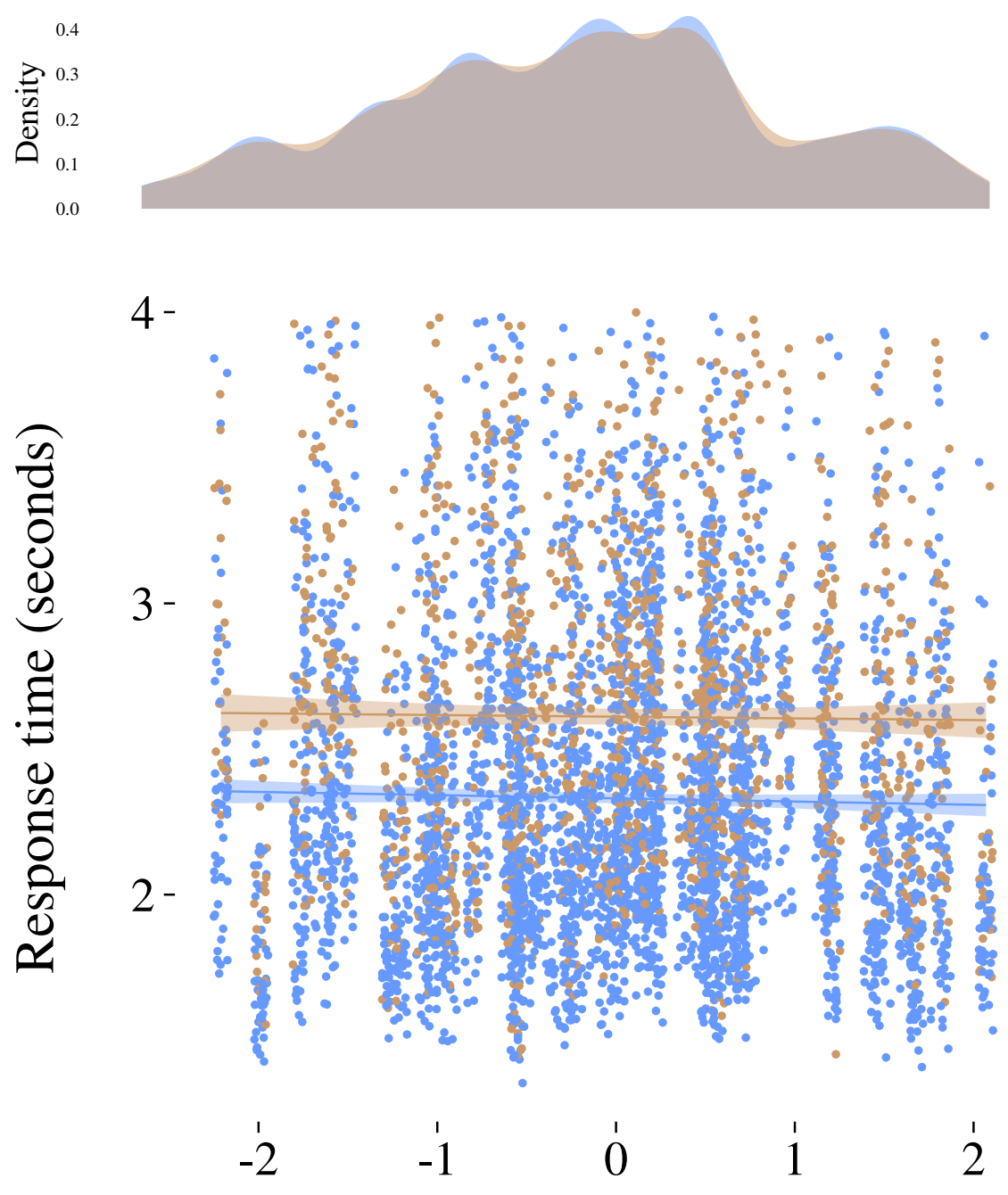

\section{HF-HRV baseline}
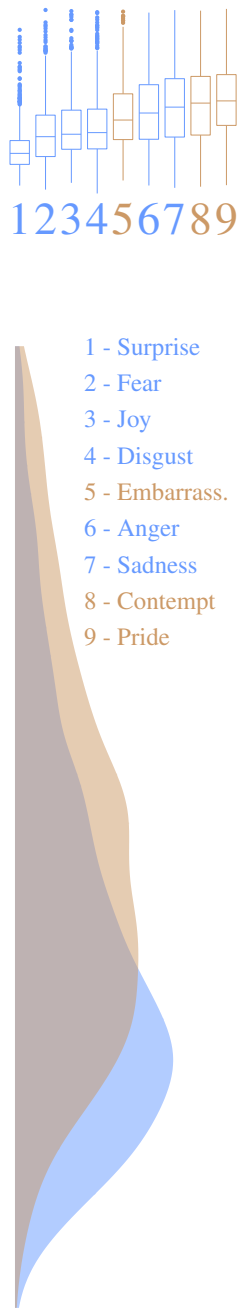

$\begin{array}{llll}0.0 & 0.4 & 0.8 & 1.2 \\ & \text { Density }\end{array}$

Figure 5. Response time for emotion identification as a function of resting HF-HRV and emotion type. Confidence regions represent $95 \%$ CIs. The top-right plot represents the ranking of the median response times relative to each EFEs. 


\section{Discussion}

We carried out a study in order to test whether HF-HRV ${ }_{540}^{539}$ was associated with better decoding of emotional facial ex- $_{541}$ pressions. Our protocol was built in order to combine the ${ }_{542}$ properties of previous studies on this subject (Bal et al., 2010; Quintana et al., 2012). We were able to measure reaction times and accuracy in an EFEs recognition task with both "basic" and "self-conscious" emotions (Schalk et al., 2011) In line with the observations of Bal et al. (2010), our results show that HF-HRV is not associated with better recognition of "basic" emotions. While "self-conscious" emotions were harder to identify than "basic" emotions, the performance of ${ }_{550}^{549}$ participants was not predicted by HF-HRV. HF-HRV does not predict emotion identification on dynamic videos of whole faces, even taking difficulty into account.

The polyvagal theory predicts that the myelinated vagal con $_{553}$ nection between the heart and the brain can foster the percep-554 tion of social cues in mammals (Porges, 2007). Quintana et $\mathrm{al}_{555}$ (2012) showed that this feature of heart-brain interactions (as 556 indexed by HF-HRV) is indeed associated with better perfor ${ }_{557}$ mances at the RMET in healthy human adults. It is generally $y_{58}$ admitted that the RMET measures the ability to read others' ${ }_{559}$ mental states. The association between HF-HRV and RMET ${ }_{560}$ performances can be interpreted as better emotion recognition ${ }_{561}$ skills in higher HF-HRV participants (Quintana et al., 2012) ${ }_{562}$ However, emotion recognition is not the only mechanism ${ }_{563}$ necessary to read other's mental states. Attentional shifting ${ }_{564}$ and inhibition play a large part in Theory of Mind (ToM) ${ }_{565}$ i.e. the ability to attribute mental states to others (R. L. C 566 Mitchell \& Phillips, 2015; Poletti, Enrici, \& Adenzato, 2012;567 Samson, 2009). Several theoretical perspective have proposed ${ }_{568}$ a framework describing the interplay between emotion percep ${ }_{569}$ tion and ToM. Many of them propose the distinction between ${ }_{570}$ decoding the emotion from external stimulation and under ${ }_{571}$ standing its meaning for the other person (R. L. C. Mitchell $\&_{572}$ Phillips, 2015). This second step is likely to require inhibition ${ }_{573}$ of one's perspective, rapid information updating, working ${ }_{574}$ memory, attentional switching between one's and the other's s75 $_{575}$ state (Carlson, Moses, \& Breton, 2002; R. L. C. Mitchell \& $\&_{576}$ Phillips, 2015; Poletti et al., 2012; Samson, 2009). As a consequence, the association between HF-HRV and 578 mind reading could also be explained by better executive ${ }_{579}$ skills and not necessarily by better emotion identification 580 abilities. Indeed, Bal et al. (2010) showed that HF-HRV was581 not associated with emotion recognition in healthy human 582 children. They used an emotion categorization task with dy-583 namic EFEs on six emotions (Porges et al., 2007). Still, it was584 not possible to put the work of Bal et al. (2010) and Quintana585 et al. (2012) in perspective because i) the population of inter-586 est was different (children vs. adults) and ii) the association ${ }_{587}$ between HF-HRV and RMET performances was observed ${ }_{588}$ when taking the items' difficulty into account: it could be ${ }_{589}$ argued that the difficulty of the task in Bal et al. (2010) did ${ }_{590}$ not allow to discriminate the association with HF-HRV. We designed a study inspired from Bal et al. (2010) but tested healthy human adults and increased the difficulty of the task by adding three more EFEs to categorize. Model comparison by AICc showed that models without HF-HRV as a parameter were always far more parsimonious than models including HF-HRV as a parameter. This was observable for reaction times, accuracy, linear and quadratic shapes, even taking the difficulty of the task into account. This design allowed to discriminate between models with and without HF-HRV, that is to say, the parsimony of the models without HF-HRV was always clearly superior to the models with HF-HRV. This support the fact that HF-HRV is not associated with emotion recognition skills.

On the basis of these results, we propose that the association between HF-HRV and performances in "mental states" reading (Quintana et al., 2012) cannot be explained by better emotion recognition skills. The more plausible explanation at this stage would rather take attentional, working memory and executive skills into account. Interestingly, recent studies clearly show that higher HF-HRV individuals perform better in many cognitive tasks depending on executive and attentional functioning. The neurovisceral integration model provides a theoretical framework (Thayer \& Lane, 2000) allowing to understand the association between HF-HRV and attention. The neural control of the heart is highly dependent on cortical inputs especially from the prefrontal cortex (PFC), the insula, and the anterior cingulate cortex (ACC). Variability observed in heart rate and mediated by the functioning of the myelinated vagus nerve is therefore largely influenced by attentional shifts, conflict monitoring, and inhibition. Conversely, it is also likely that afferent feed-backs from the heart can influence the central nervous system, therefore creating dynamic loops between the heart and the brain, fostering the adaptation of the organisms to internal and external demands. Neuroimaging studies bring evidence toward an important overlap between central nervous system activities associated with HRV (Thayer, Åhs, Fredrikson, Sollers, \& Wager, 2012) and with ToM (Schurz, Radua, Aichhorn, Richlan, \& Perner, 2014). The medial PFC (mPFC), the insula and the ACC play a large part in cardiovascular control and ToM. These areas show connections with the temporo-parietal junction (TPJ). It has been suggested that the TPJ is mainly involved in inferences about short-term intentions while more durable mental states could rather be taken over by the mPFC (Van Overwalle, 2009). The mPFC is also involved in inhibitory functions and interconnected with the ACC associated with cognitive control and conflict monitoring and with the insula underlying body states integration (Lane et al., 2009; Mier et al., 2010; Reeck, Ames, \& Ochsner, 2016; Thayer \& Lane, 2009). Therefore, brain areas involved in cardiovascular control and characterizing differences in HRV are often found associated with executive functioning, attentional regulation, 
and switching between one's and other's body states rather 644 than emotion identification.

645

Even if we did not measure sensorimotor activity of the face 646 during the tasks, we made the hypothesis that sensorimotor 647 simulation would play an important part in the detection of 648 emotions (Wood et al., 2016). This hypothesis was important 649 in order to test the polyvagal proposition (Porges, 2001) ac-650 cording to which neural cardiovascular control is associated 651 with neural sensorimotor control of the head and face muscles, both at an anatomical and at a functional level. In this ${ }_{652}$ perspective, our result does not validate that HF-HRV and sensorimotor skills are associated in order to perform a perceptive task such as decoding EFEs. Thus, it is plausible that ${ }^{653}$ HF-HRV predicts social skills (Beffara, Bret, Vermeulen, $\&^{654}$ Mermillod, 2016; Miller, Kahle, \& Hastings, 2015) at another ${ }^{655}$ level. Attentional skills have already been suggested as the ${ }^{656}$ cognitive mechanism linking HF-HRV and social functioning ${ }^{657}$ (Keltner, Kogan, Piff, \& Saturn, 2014). Obviously, we did ${ }^{658}$ not test this hypothesis in this study. However, as attention ${ }_{659}$ is a strong necessity to apply theory of mind (Lin, Keysar, $\&_{660}$ Epley, 2010) aside from decoding facial patterns, it is likely ${ }_{661}$ that the ability of higher HF-HRV individuals to process social ${ }_{662}$ signals is not due to better sensori-motor control but rather to better attentional or executive skills (Park \& Thayer, 2014) 663 Obviously, this proposition still needs to be specifically tested 664 A solid set of studies highlight the association between HF-665 HRV and working memory (Hansen, Johnsen, \& Thayer, ${ }^{666}$ 2003; Hansen, Johnsen, Sollers, Stenvik, \& Thayer, 2004), ${ }^{667}$ inhibition and attention switching (Kimhy et al., 2013), and ${ }^{668}$ more flexible attentional engagement and disengagement toward negative emotional stimuli (Park \& Thayer, 2014; Park, ${ }_{670}^{669}$ Van Bavel, Vasey, Egan, \& Thayer, 2012; Park, Vasey, Van ${ }_{671}^{670}$ Bavel, \& Thayer, 2013). Consequently, whether at neuroimaging or behavioral level, better cognitive skills associated with higher resting state HF-HRV appear to be a more reliable candidate for explaining more accurate mind reading, while 674 emotion identification abilities did not show substantial as ${ }_{675}$ sociation with HF-HRV in our study. While further studies 676 are needed to clearly establish the mediation of the HF-HRV ${ }_{677}$ ToM link by executive functioning, we suggest that domain-678 general cognitive mechanisms (C. Heyes, 2014; Cecilia Heyes ${ }_{679}$ 2016a, 2016b; Cecilia Heyes \& Pearce, 2015) should be considered when studying in the functional association between ${ }^{680}$ HF-HRV and the social life.

Conclusions. Heart-brain interactions are proposed to ${ }^{682}$ Conclusions. Heart-brain interactions are proposed to underlie socio-emotional skills (Porges, 2007). It has been ${ }_{684}$ shown that resting HF-HRV is associated with mental states ${ }_{685}^{64}$ reading (Quintana et al., 2012). These authors suggested that ${ }_{686}^{685}$ HF-HRV was linked to emotion recognition abilities. However, the current study does not allow to conclude that resting ${ }_{687}$ HF-HRV predict emotion recognition, even taking emotion 688 type into account. Further studies should examine the role of 689 executive functioning as a mediator of the HF-HRV - ToM 690 association. Domain-general cognitive skills could account for the role of HF-HRV in social functioning.

Aknowledgements. We thank Amélie Baldini and Elie Bes for technical support in data collection. We also thank all the participants for taking part in the study. We thank Pierre Maurage and Delphine Grynberg for their useful comments and constructive remarks. This research was funded by the french CNRS and the Institut Universitaire de France.

\section{References}

Akselrod, S., Gordon, D., Ubel, F. F., Shannon, D. D., Berger, A., Cohen, R. R., ... Cohen, R. R. (1981). Power spectrum analysis of heart rate fluctuation: a quantitative probe of beat-to-beat cardiovascular control. Science, 213(4504), 220-22. doi:10.1126/science.6166045

Amodio, D. M., \& Frith, C. D. (2006). Meeting of minds: the medial frontal cortex and social cognition. Nature Reviews. Neuroscience, 7(4), 268-77. doi:10.1038/nrn1884

Bal, E., Harden, E., Lamb, D., Van Hecke, A. V., Denver, J. W., \& Porges, S. W. (2010). Emotion recognition in children with autism spectrum disorders: Relations to eye gaze and autonomic state. Journal of Autism and Developmental Disorders, 40(3), 358370. doi:10.1007/s10803-009-0884-3

Baron-Cohen, S., Golan, O., \& Ashwin, E. (2009). Can emotion recognition be taught to children with autism spectrum conditions? Philosophical Transactions of the Royal Society B: Biological Sciences, 364(1535), 3567-3574. doi:10.1098/rstb.2009.0191

Baron-Cohen, S., Jolliffe, T., Mortimore, C., \& Robertson, M. (1997). Another advanced test of theory of mind: Evidence from very high functioning adults with autism or Asperger syndrome. Journal of Child Psychology and Psychiatry and Allied Disciplines, 38(7), 813822. doi:10.1111/j.1469-7610.1997.tb01599.x

Baron-Cohen, S., Wheelwright, S., Hill, J., Raste, Y., \& Plumb, I. (2001). The "Reading the Mind in the Eyes" Test revised version: a study with normal adults, and adults with Asperger syndrome or highfunctioning autism. Journal of Child Psychology and Psychiatry, and Allied Disciplines, 42(2), 24151. doi:10.1111/1469-7610.00715

Beffara, B., Bret, A. G., Vermeulen, N., \& Mermillod, M. (2016). Resting high frequency heart rate variability selectively predicts cooperative behavior. Physiology $\mathcal{E}$ Behavior, 164, 417-428. 
doi:10.1016/j.physbeh.2016.06.011

738

Berntson, G. G., Bigger Jr., T., Eckberg, D. L., Grossman, P., Kaufmann, P. G., Malik, M., ... Molen, M. W. van 740 der. (1997). Heart rate variability: origins, methods,, 41 and interpretive caveats. Psychophysiology, 34(6),742 623-648. doi:10.1111/j.1469-8986.1997.tb02140.X743

Berntson, G. G., Cacioppo, J. T., \& Quigley, K. S. (1993) ${ }_{745}^{744}$ Respiratory sinus arrhythmia: Autonomic origins, physiological mechanisms, and psychophysiological 746 implications. Psychophysiology, 30(2), 183-196 747 doi:10.1111/j.1469-8986.1993.tb01731.x 748

Berntson, G. G., Norman, G. J., Hawkley, L. C., \& Cacioppo ${ }_{750}^{749}$ J. T. (2008). Cardiac autonomic balance versus cardiac regulatory capacity. Psychophysiology, 45(4),751 643-652. doi:10.1111/j.1469-8986.2008.00652.x 752

Bertels, J., Deliens, G., Peigneux, P., \& Destrebecqz, A. (2014). The Brussels Mood Inductive Audio Sto-754 ries (MIAS) database. Behavior Research Methods,755 1098-1107. doi:10.3758/s13428-014-0445-3

Boyer, P., Firat, R., \& Leeuwen, F. van. (2015). Safety, Threat,757 and Stress in Intergroup Relations: A Coalitional In-758 dex Model. Perspectives on Psychological Science,759 10(4), 434-450. doi:10.1177/1745691615583133 760

Briancon, S., Bonsergent, E., Agrinier, N., Tessier, S. ${ }_{762}^{761}$ Legrand, K., Lecomte, E., ... (ptg), P. T. G. (2010). PRALIMAP: study protocol for a high school-based,763 factorial cluster randomised interventional trial of ${ }_{764}$ three overweight and obesity prevention strategies 765 Trials, 11(1), 119. doi:10.1186/1745-6215-11-119 766

Brooks, K. A., Carter, J. G., Dawes, J. J., A Brooks, K.,767 Brooks, K. A., Carter, J. G., . . Dawes, J. J. (2013) 768 A Comparison of VO2 Measurement Obtained by a769 Physiological Monitoring Device and the Cosmed 770 Quark CPET. Journal Of Novel Physiotherapies,771 3(3), 1-2. doi:10.4172/2165-7025.1000126

Brown, S. L., \& Brown, R. M. (2015). Connecting proso-773 cial behavior to improved physical health: Contri-774 butions from the neurobiology of parenting. Neu-775 roscience and Biobehavioral Reviews, 55, 1-17. doi:10.1016/j.neubiorev.2015.04.004

Burnham, K. P., \& Anderson, R. (2004). Multimodel In-778 ference: Understanding AIC and BIC in Model Se-779 lection. Sociological Methods E Research, 33(2), 261-304. doi:10.1177/0049124104268644 780

Burnham, K. P., Anderson, D. R., \& Huyvaert, K. P. (2011) z82 AIC model selection and multimodel inference in behavioral ecology: Some background, observations, and comparisons. Behavioral Ecology and Sociobiology, 65(1), 23-35. doi:10.1007/s00265-010-1029-6

Cacioppo, J. T., Berntson, G. G., Binkley, P. F., Quigley, K. S., Uchino, B. N., \& Fieldstone, A. (1994). Autonomic cardiac control. II. Noninvasive indices and basal response as revealed by autonomic blockades. Psychophysiology, 31(6), 586-598. doi:10.1111/j.14698986.1994.tb02351.x

Carlson, S. M., Moses, L. J., \& Breton, C. (2002). How Specific is the Relation between Executive Function and Theory of Mind? Contributions of Inhibitory Control and Working Memory. Infant and Child Development, 11(2), 73-92. doi:10.1002/icd.298

Cânovas, M., Domingues, A., \& Sanches, J. M. (2011). Real Time HRV with smartphone System architecture. In RecPad (pp. 126-127).

Coote, J. H. (2013). Myths and realities of the cardiac vagus. The Journal of Physiology, 591(Pt 17), 4073-4085. doi:10.1113/jphysiol.2013.257758

Craig, C. L., Marshall, A. L., Sjöström, M., Bauman, A. E., Booth, M. L., Ainsworth, B. E., ... Oja, P. (2003). International physical activity questionnaire: 12-country reliability and validity. Medicine and Science in Sports and Exercise, 35(8), 1381-95. doi:10.1249/01.MSS.0000078924.61453.FB

Denver, J. W., Reed, S. F., \& Porges, S. W. (2007). Methodological issues in the quantification of respiratory sinus arrhythmia. Biological Psychology, 74(2), 286294. doi:10.1016/j.biopsycho.2005.09.005

Dimberg, U., Thunberg, M., \& Elmehed, K. (2000). Unconscious facial reactions to emotional facial expressions. Psychological Science : A Journal of the American Psychological Society /APS, 11(1), 86-89. doi:10.1111/1467-9280.00221

Ford, T. W., \& McWilliam, P. N. (1986). The effects of electrical stimulation of myelinated and non-myelinated vagal fibres on heart rate in the rabbit. J Physiol, 380(12), 341-347. doi:10.1113/jphysiol.1986.sp016289

Gallese, V., \& Caruana, F. (2016). Embodied Simulation: Beyond the Expression/Experience Dualism of Emotions. Trends in Cognitive Sciences, 20(6), 397-398. doi:10.1016/j.tics.2016.03.010

García, C. A., Otero, A., Vila, X., \& Márquez, D. G. (2013). A new algorithm for wavelet-based heart rate variability analysis. Biomedical Signal Processing and Con- 
trol, 8(6), 542-550. doi:10.1016/j.bspc.2013.05.006829

Hagströmer, M., Oja, P., \& Sjöström, M. (2006). The International Physical Activity Questionnaire 831 (IPAQ): a study of concurrent and construct valid-832 ity. Public Health Nutrition, 9(06), 1127-1132 833 doi:10.1079/PHN2005898

Hansen, A. L., Johnsen, B. H., \& Thayer, J. F. (2003). Vagal 835 influence on working memory and attention. Interna $a_{836}$ tional Journal of Psychophysiology, 48(3), 263-274 ${ }_{837}$ doi:10.1016/S0167-8760(03)00073-4

Hansen, A. L., Johnsen, B. H., Sollers, J. J., Stenvik, K., \& Thayer, J. F. (2004). Heart rate variabil-840 ity and its relation to prefrontal cognitive func-841 tion: The effects of training and detraining. Euro -842 pean Journal of Applied Physiology, 93(3), 263-272 ${ }_{843}$ doi:10.1007/s00421-004-1208-0

Heathers, J. A. J. (2014). Everything Hertz: Method-845 ological issues in short-term frequency-domain ${ }_{846}$ HRV. Frontiers in Physiology, 5 MAY(May), $177_{847}$ doi:10.3389/fphys.2014.00177

Hegyi, G., \& Garamszegi, L. Z. (2011). Using information ${ }_{849}$ theory as a substitute for stepwise regression in ecol-850 ogy and behavior. Behavioral Ecology and Sociobi- - $_{51}$ ology, 65(1), 69-76. doi:10.1007/s00265-010-1036-852 7

Hewig, J., Hagemann, D., Seifert, J., Gollwitzer, M., Nau-854 mann, E., \& Bartussek, D. (2005). Brief Re-855 port. Cognition E Emotion, 19(7), 1095-1109 856 doi:10.1080/02699930541000084

Heyes, C. (2014). Submentalizing: I Am Not Really Reading ${ }_{858}$ Your Mind. Perspectives on Psychological Science,, 59 9(2), 131-143. doi:10.1177/1745691613518076

Heyes, C. (2016a). Blackboxing: social learning strate-861 gies and cultural evolution. Philosophical Trans-862 actions of the Royal Society B: Biological Sciences,, 63 371(1693), 20150369. doi:10.1098/rstb.2015.0369 864

Heyes, C. (2016b). Who Knows? Metacognitive Social Learn-865 ing Strategies. Trends in Cognitive Sciences, 20(3),866 204-213. doi:10.1016/j.tics.2015.12.007 867

Heyes, C., \& Pearce, J. M. (2015). Not-so-social learning ${ }^{868}$ strategies. Proceedings of the Royal Society B: Bio- ${ }_{870}^{869}$ logical Sciences, 282(1802), 20141709-20141709. doi:10.1098/rspb.2014.1709

Iorfino, F., Alvares, G. A., Guastella, A. J., \& Quintana, D. S ${ }_{873}^{872}$ (2016). Cold face test-induced increases in heart rate ${ }_{874}$ variability are abolished by engagement in a social cognition task. Journal of Psychophysiology, 30(1), 38-46. doi:10.1027/0269-8803/a000152

Jack, R. E., \& Schyns, P. G. (2015). The Human Face as a Dynamic Tool for Social Communication. Current Biology, 25(14), R621-R634. doi:10.1016/j.cub.2015.05.052

Jack, R. E., Sun, W., Delis, I., Garrod, O. G. B., \& Schyns, P. G. (2016). Four not six: Revealing culturally common facial expressions of emotion. Journal of Experimental Psychology: General, 145(6), 708730. doi: $10.1037 / \mathrm{xge} 0000162$

Johnstone, J. A., Ford, P. A., Hughes, G., Watson, T., \& Garrett, A. T. (2012a). Bioharness( $\left({ }^{\mathrm{TM}}\right)$ multivariable monitoring device: part. I: validity. Journal of Sports Science $\mathcal{E}$ Medicine, 11(3), 400-8.

Johnstone, J. A., Ford, P. A., Hughes, G., Watson, T., \& Garrett, A. T. (2012b). Bioharness( ${ }^{\mathrm{TM}}$ ) Multivariable Monitoring Device: Part. II: Reliability. Journal of Sports Science E Medicine, 11(3), 409-17.

Johnstone, J. A., Ford, P. A., Hughes, G., Watson, T., Mitchell, A. C. S., \& Garrett, A. T. (2012). Field based reliability and validity of the bioharness ${ }^{\mathrm{TM}}$ multivariable monitoring device. Journal of Sports Science $\mathcal{E}$ Medicine, 11(4), 643-52.

Jones, J. F. X., Wang, Y., \& Jordan, D. (1995). Heart-rate responses to selective stimulation of cardiac vagal-c fibers in anesthetized cats, rats and rabbits. Journal of Physiology (London), 489, 203-214.

Jordan, D. (2005). Vagal control of the heart: central serotonergic (5-HT) mechanisms. Exp. Physiol., 90(2), 175-181. doi:10.1113/expphysiol.2004.029058

Kamath, M. V., \& Fallen, E. L. (1993). Power spectral analysis of heart rate variability: a noninvasive signature of cardiac autonomic function. Critical Reviews in Biomedical Engineering, 21(3), 245-311. doi:8243093

Kamath, M. V., Upton, a R., Talalla, A., \& Fallen, E. L. (1992). Effect of vagal nerve electrostimulation on the power spectrum of heart rate variability in man. Pacing and Clinical Electrophysiology : PACE, 15(2), 235-43. Retrieved from http://onlinelibrary.wiley.com/doi/10. 1111/j.1540-8159.1992.tb03067.x/abstract

Kamath, M. V., Upton, A. R. M., Talalla, A., \& Fallen, E. L. (1992). Neurocardiac responses to vagoafferent electrostimulation in humans. PACE - Pacing and Clinical Electrophysiology, 15(10 II), 1581-1587. 
doi:10.1111/j.1540-8159.1992.tb02937.x

Kass, R., \& Raftery, A. (1995). Bayes Factors. Journal of the ${ }_{924}^{923}$ American Statistical Association, 90(430), 773-795. doi:10.1080/01621459.1995.10476572

Keltner, D., Kogan, A., Piff, P. K., \& Saturn, S. R. (2014) ${ }_{9_{227}}^{926}$ The sociocultural appraisals, values, and emotions ${ }_{928}$ (SAVE) framework of prosociality: core processes from gene to meme. Annual Review of Psychology, ${ }_{930}$ 65, 425-60. doi:10.1146/annurev-psych-010213115054

Kemper, K. J., Hamilton, C., \& Atkinson, M. (2007) ${ }_{933}^{932}$ Heart rate variability: Impact of differences in ${ }_{934}$ outlier identification and management strategies ${ }_{935}$ on common measures in three clinical populations. Pediatric Research, 62(3), 337-342936 doi:10.1203/PDR.0b013e318123fbcc

Kimhy, D., Crowley, O. V., McKinley, P. S., Burg, M. M. ${ }_{939}^{938}$ Lachman, M. E., Tun, P. A., . . Sloan, R. P. (2013) ${ }_{940}$ The association of cardiac vagal control and execu- ${ }_{941}$ tive functioning - Findings from the MIDUS study. Journal of Psychiatric Research, 47(5), 628-635942 doi:10.1016/j.jpsychires.2013.01.018

Kobayashi, H. (2009). Does paced breathing improve the re- ${ }^{944}$ producibility of heart rate variability measurements? Journal of Physiological Anthropology, 28(5), 225-946 230. doi:10.2114/jpa2.28.225

Kowalewski, M. A., \& Urban, M. (2004). Short-and ${ }_{949}^{948}$ long-term reproducibility of autonomic measures ${ }_{950}$ in supine and standing positions. Clinical Science, 106(1), 61-66. doi:10.1042/CS20030119

Lane, R. D., McRae, K., Reiman, E. M., Chen, K., Ahern, G ${ }_{953}^{952}$ L., \& Thayer, J. F. (2009). Neural correlates of heart ${ }_{954}$ rate variability during emotion. NeuroImage, 44(1) ${ }_{955}$ 213-222. doi:10.1016/j.neuroimage.2008.07.056

Larsen, P. D., Tzeng, Y. C., Sin, P. Y. W., \& Galletly, D. C ${ }_{957}^{956}$ (2010). Respiratory sinus arrhythmia in conscious ${ }_{958}$ humans during spontaneous respiration. Respiratory Physiology and Neurobiology, 174(1-2), 111-118959 doi:10.1016/j.resp.2010.04.021

Lin, S., Keysar, B., \& Epley, N. (2010). Reflexively mindblind: Using theory of mind to interpret be ${ }^{962}$ havior requires effortful attention. Journal of Experimental Social Psychology, 46(3), 551-556964 doi:10.1016/j.jesp.2009.12.019

Lovibond, P. F., \& Lovibond, S. H. (1995). The struc- ${ }^{966}$ ture of negative emotional states: Comparison of ${ }_{968}$ the depression anxiety stress scales (DASS) with the Beck Depression and Anxiety Inventories. Behaviour Research and Therapy, 33(3), 335-343. doi:10.1037/1040-3590.10.2.176

Lumma, A. L., Kok, B. E., \& Singer, T. (2015). Is meditation always relaxing? Investigating heart rate, heart rate variability, experienced effort and likeability during training of three types of meditation. International Journal of Psychophysiology, 97(1), 38-45. doi:10.1016/j.ijpsycho.2015.04.017

Mier, D., Lis, S., Neuthe, K., Sauer, C., Esslinger, C., Gallhofer, B., \& Kirsch, P. (2010). The involvement of emotion recognition in affective theory of mind. Psychophysiology, 47(6), 1028-1039. doi:10.1111/j.1469-8986.2010.01031.x

Miller, J. G., Kahle, S., \& Hastings, P. D. (2015). Roots and Benefits of Costly Giving: Children Who Are More Altruistic Have Greater Autonomic Flexibility and Less Family Wealth. Psychological Science, 26(7), 0956797615578476. doi:10.1177/0956797615578476

Mitchell, R. L. C., \& Phillips, L. H. (2015). The overlapping relationship between emotion perception and theory of mind. Neuropsychologia, 70, 1-10. doi:10.1016/j.neuropsychologia.2015.02.018

Muhtadie, L., Koslov, K., Akinola, M., \& Mendes, W. B. (2015). Vagal flexibility: A physiological predictor of social sensitivity. Journal of Personality and Social Psychology, 109(1), 106-120. doi:10.1037/pspp0000016

Neuberg, S. L., Kenrick, D. T., \& Schaller, M. (2011). Human threat management systems: Selfprotection and disease avoidance. Neuroscience and Biobehavioral Reviews, 35(4), 1042-1051. doi:10.1016/j.neubiorev.2010.08.011

Niedenthal, P. M. (2007). Embodying emotion. Science, 316(5827), 1002-1005. doi:10.1126/science. 1136930

Park, G., \& Thayer, J. F. (2014). From the heart to the mind: Cardiac vagal tone modulates top-down and bottom-up visual perception and attention to emotional stimuli. Frontiers in Psychology, 5(MAY), 278. doi:10.3389/fpsyg. 2014.00278

Park, G., Van Bavel, J. J., Vasey, M. W., Egan, E. J. L., \& Thayer, J. F. (2012). From the heart to the mind's eye: Cardiac vagal tone is related to visual perception of fearful faces at high spatial frequency. Biological Psychology, 90(2), 171-178. 
doi:10.1016/j.biopsycho.2012.02.012

Park, G., Vasey, M. W., Van Bavel, J. J., \& Thayer, J. F. (2013) ${ }_{1017}^{1016}$ Cardiac vagal tone is correlated with selective attention to neutral distractors under load. Psychophysi $i_{1019}$ ology, 50(4), 398-406. doi:10.1111/psyp.12029

Piferi, R. L., Kline, K. A., Younger, J., \& Lawler, K. A. $(2000)_{102}^{1020}$ An alternative approach for achieving cardiovascular baseline: Viewing an aquatic video. Interna-2 tional Journal of Psychophysiology, 37(2), 207-217 ${ }_{1024}$ doi:10.1016/S0167-8760(00)00102-1

Pinna, G. D., Maestri, R., Torunski, A., DanilowiczSzymanowicz, L., Szwoch, M., La Rovere, M. T., \& Raczak, G. (2007). Heart rate variability measures: a fresh look at reliability. Clinical Science, 113(3) ${ }_{1022}^{1028}$ 131-40. doi:10.1042/CS20070055

Poletti, M., Enrici, I., \& Adenzato, M. (2012). Cognitive $e_{103}^{1030}$ and affective Theory of Mind in neurodegenerative diseases: Neuropsychological, neuroanatom- ${ }_{1033}^{-2}$ ical and neurochemical levels. Neuroscience $e^{1033}$ and Biobehavioral Reviews, 36(9), 2147-2164 ${ }_{1035}^{1034}$ doi:10.1016/j.neubiorev.2012.07.004

Porges, S. W. (1995). Cardiac vagal tone: A physiological index of stress. Neuroscience and Biobehav $v_{1038}^{-}$ ioral Reviews, 19(2), 225-233. doi:10.1016/0149-1038 7634(94)00066-A

Porges, S. W. (1997). Emotion: An evolutionary by ${ }^{1041}$ product of the neural regulation of the autonomic nervous system. Annals of the New York ${ }_{1043}^{1042}$ Academy of Sciences, 807(1 Integrative N), 62-77 ${ }_{1044}^{1043}$ doi:10.1111/j.1749-6632.1997.tb51913.x

Porges, S. W. (1998). Love: An emergent property of the mammalian autonomic nervous system. Psychoneuroendocrinology, 23(8), 837-861 ${ }_{1048}^{1047}$ doi:10.1016/S0306-4530(98)00057-2

1049

Porges, S. W. (2001). The polyvagal theory: Phylogenetic ${ }^{1050}$ substrates of a social nervous system. International Journal of Psychophysiology, 42(2), 123-146. doi:10.1016/S0167-8760(01)00162-3

1053

Porges, S. W. (2003). The Polyvagal Theory: Phyloge $e^{1054}$ netic contributions to social behavior. Physiology ${ }^{1055}$ and Behavior, 79(3), 503-513. doi:10.1016/S0031-1056 9384(03)00156-2

Porges, S. W. (2007). The polyvagal perspective.058 Biological Psychology, 74(2), 116-143. ${ }^{1059}$ doi:10.1016/j.biopsycho.2006.06.009 1060

Porges, S. W., Cohn, J., Bal, E., \& Lamb, D. (2007) ${ }^{1061}$
The Dynamic Affect Recognition Evaluation software. Brain-Body Center, University of Illinois at Chicago. Retrieved from http: //www.polyvagalscience.com/index.php/software/ dynamic-affect-recognition-evaluation-dare

Prinsloo, G. E., Rauch, H. G. L., Lambert, M. I., Muench, F., Noakes, T. D., \& Derman, W. E. (2011). The effect of short duration heart rate variability (HRV) biofeedback on cognitive performance during laboratory induced cognitive stress. Applied Cognitive Psychology, 25(5), 792-801. doi:10.1002/acp.1750

Quintana, D. S., \& Heathers, J. A. J. (2014). Considerations in the assessment of heart rate variability in biobehavioral research. Frontiers in Psychology, 5(JUL), 1-10. doi:10.3389/fpsyg.2014.00805

Quintana, D. S., Guastella, A. J., Outhred, T., Hickie, I. B., \& Kemp, A. H. (2012). Heart rate variability is associated with emotion recognition: Direct evidence for a relationship between the autonomic nervous system and social cognition. International Journal of Psychophysiology, 86(2), 168-172. doi:10.1016/j.ijpsycho.2012.08.012

Ramasawmy, S., \& Gilles, P. Y. (2012). The internal and external validities of the Depression Anxiety Stress Scales (DASS-21). International Journal of Psychology, 47(sup1), 1-41. doi:10.1080/00207594.2012.709085

Reeck, C., Ames, D. R., \& Ochsner, K. N. (2016). The Social Regulation of Emotion: An Integrative, CrossDisciplinary Model. Trends in Cognitive Sciences, 20(1), 47-63. doi:10.1016/j.tics.2015.09.003

Rodríguez-Liñares, L., Méndez, A., Lado, M., Olivieri, D., Vila, X., \& Gómez-Conde, I. (2011). An open source tool for heart rate variability spectral analysis. Computer Methods and Programs in Biomedicine, 103(1), 39-50. doi:10.1016/j.cmpb.2010.05.012

Salanave, B., Vernay, M., Szego, E., Malon, A., Deschamps, V., Hercberg, S., \& Castetbon, K. (2012). Physical activity patterns in the French 18-74-year-old population: French Nutrition and Health Survey (Etude Nationale Nutrition Santé, ENNS) 20062007. Public Health Nutrition, 15(11), 2054-9. doi: $10.1017 / \mathrm{S} 1368980012003278$

Samson, D. (2009). Reading other people's mind: insights from neuropsychology. Journal of Neuropsychology, 3(Pt 1), 3-16. doi:10.1348/174866408X377883

Schaefer, A., Nils, F. F., Sanchez, X., \& Philippot, P. (2010). 
HF-HRV NOT ASSOCIATED WITH EMOTION RECOGNITION

Assessing the effectiveness of a large database of ${ }_{108}$ emotion-eliciting films: A new tool for emotion researchers. Cognition E Emotion, 24(7), 1153-1172.109 doi:10.1080/02699930903274322

Schalk, J. van der, Hawk, S. T., Fischer, A. H., \& Doosje,112 B. (2011). Moving faces, looking places: Validation of the Amsterdam Dynamic Facial Ex-113 pression Set (ADFES). Emotion, 11(4), 907-920.14 doi: $10.1037 / \mathrm{a} 0023853$

Schurz, M., Radua, J., Aichhorn, M., Richlan, F., \& Perner,117 J. (2014). Fractionating theory of mind: A metaanalysis of functional brain imaging studies. $\mathrm{Neu}^{1118}$ roscience and Biobehavioral Reviews, 42, 9-34.119 doi:10.1016/j.neubiorev.2014.01.009

Sherwood, C. C. (2005). Comparative anatomy of the facial motor nucleus in mammals, with an analysis of neu-122 ron numbers in primates. Anatomical Record - Part $A^{123}$ Discoveries in Molecular, Cellular, and Evolutionary ${ }^{124}$ Biology, 287(1), 1067-1079. doi:10.1002/ar.a.20259 $9^{125}$

Simmons, J. P., Nelson, L. D., \& Simonsohn, U. (2012).127 A 21 word solution. SPSP Dialogue, 1-4. doi: $10.2139 /$ ssrn. 2160588

Singer, T., \& Klimecki, O. M. (2014). Empathy and com ${ }_{130}$ passion. Current Biology, 24(18), R875-R878. doi:10.1016/j.cub.2014.06.054

Snipes, M., \& Taylor, D. C. (2014). Model selection and ${ }_{133}$ Akaike Information Criteria: An example from wine ${ }_{134}$ ratings and prices. Wine Economics and Policy, 3(1), 3-9. doi:10.1016/j.wep.2014.03.001

Spoor, J. R., \& Kelly, J. R. (2004). The evolutionary signifiмзз cance of affect in groups: Communication and group bonding. Group Processes $\mathcal{F}$ Intergroup Relations, ${ }^{1138}$ 7(4), 398-412. doi:10.1177/1368430204046145 1139

Symonds, M. R. E., \& Moussalli, A. (2011). A brief guide ${ }_{141}$ to model selection, multimodel inference and model averaging in behavioural ecology using Akaike' ${ }^{142}$ information criterion. Behavioral Ecology and So ${ }^{1143}$ ciobiology, 65(1), 13-21. doi:10.1007/s00265-010144 1037-6

Taborsky, B., \& Oliveira, R. F. (2012). Social com-1146 petence: An evolutionary approach. Trends ${ }^{1147}$ in Ecology and Evolution, 27(12), 679-688.148 doi:10.1016/j.tree.2012.09.003

Task Force of the European Society of Cardiology the North American Society of Pacing Electrophysiol-151 ogy. (1996). Guidelines Heart rate variability. Euro ${ }^{1152}$ pean Heart Journal, 17, 354-381.

Thayer, J. F., \& Lane, R. D. (2000). A model of neurovisceral integration in emotion regulation and dysregulation. Journal of Affective Disorders, 61(3), 201-216. doi:10.1016/S0165-0327(00)00338-4

Thayer, J. F., \& Lane, R. D. (2009). Claude Bernard and the heart-brain connection: Further elaboration of a model of neurovisceral integration. Neuroscience and Biobehavioral Reviews, 33(2), 81-88. doi:10.1016/j.neubiorev.2008.08.004

Thayer, J. F., \& Sternberg, E. (2006). Beyond heart rate variability: Vagal regulation of allostatic systems. Annals of the New York Academy of Sciences, 1088(1), 361-372. doi:10.1196/annals.1366.014

Thayer, J. F., Åhs, F., Fredrikson, M., Sollers, J. J., \& Wager, T. D. (2012). A meta-analysis of heart rate variability and neuroimaging studies: Implications for heart rate variability as a marker of stress and health. Neuroscience and Biobehavioral Reviews, 36(2), 747-756. doi:10.1016/j.neubiorev.2011.11.009

Tracy, J. L., \& Robins, R. W. (2008). The automaticity of emotion recognition. Emotion, 8(1), 81-95. doi:10.1037/1528-3542.8.1.81

Tracy, J. L., Robins, R. W., \& Schriber, R. A. (2009). Development of a FACS-verified set of basic and selfconscious emotion expressions. Emotion, 9(4), 554559. doi:10.1037/a0015766

Van Overwalle, F. (2009). Social cognition and the brain: A meta-analysis. Human Brain Mapping, 30(3), 829858. doi:10.1002/hbm. 20547

Villarejo, M., Zapirain, B., \& Zorrilla, A. (2013). Algorithms Based on CWT and Classifiers to Control Cardiac Alterations and Stress Using an ECG and a SCR. Sensors, 13(5), 6141-6170. doi:10.3390/s130506141

Ward, A., \& Webster, M. (2016). Sociality: The Behaviour of Group-Living Animals. Cham: Springer International Publishing. doi:10.1007/978-3-319-28585-6

Wells, R., Outhred, T., Heathers, J. A. J., Quintana, D. S., \& Kemp, A. H. (2012). Matter Over Mind: A Randomised-Controlled Trial of Single-Session Biofeedback Training on Performance Anxiety and Heart Rate Variability in Musicians. PLoS ONE, 7(10), e46597. doi:10.1371/journal.pone.0046597

Wood, A., Rychlowska, M., Korb, S., \& Niedenthal, P. M. (2016). Fashioning the Face: Sensorimotor Simulation Contributes to Facial Expression Recogni- 
bioRxiv preprint doi: https://doi.org/10.1101/077784; this version posted September 27, 2016. The copyright holder for this preprint (which was not certified by peer review) is the author/funder, who has granted bioRxiv a license to display the preprint in perpetuity. It is made available under aCC-BY-NC-ND 4.0 International license.

18

BRICE BEFFARA ${ }^{1,2,3}$, NICOLAS VERMEULEN $^{3,4}$, MARTIAL MERMILLOD $^{1,2}$

tion. Trends in Cognitive Sciences, 20(3), 227-240. doi:10.1016/j.tics.2015.12.010

Yoon, J. H., Shah, R. S., Arnoudse, N. M., \& De La Garza, R. (2014). Remote physiological monitoring of acute cocaine exposure. Journal of Medical Engineering $\mathcal{E}$ Technology, 38(5), 244-250. doi:10.3109/03091902.2014.902513

Zephyr. (2014). Zephyr. Retrieved from https://www. zephyranywhere.com 